\title{
Determining information flow through a network of simulated neurons
}

\author{
Cathal J Cooney*, Eoin Lynch \\ From Twenty First Annual Computational Neuroscience Meeting: CNS*2012 \\ Decatur, GA, USA. 21-26 July 2012
}

We feel that by applying Network Theory to neuroscience that we can determine how information can pass through a network of neurons. In vivo data would only provide a partial network, so we could not examine the information flow properly. Therefore, we decided to simulate a network of neurons, so that we could have control over the input, and so that we could see how each neuron reacts with its neighbors.

We simulate our network of neurons using the Adaptive Exponential Integrate-and-Fire (aEIF) model [1]. We let the network of neurons have the same characteristics as we would expect from a network of neurons in the brain.

We determine, from the output data, which neurons have a strong influence on when other neurons spike using Incremental Mutual Information (IMI) [2]. We model the network mathematically with the strength of links determined by the peak IMI to get a directed network. We form the bibliographic coupling network and cluster it effectively by using Newman's eigenvalue algorithm for maximizing modularity [3]. By comparing these clusters back to the directed network, we get a map of information flow through the network of neurons.

We feel that this could be a useful method for analyzing datasets of simultaneous neurons as such datasets get larger with advances in recording equipment.

Published: 16 July 2012

\section{References}

1. Brette R, Gerstner W: Adaptive Exponential Integrate-and-Fire Model as an Effective Description of Neuronal Activity. J Neurophysiol 2005, 94:3637-3642.

2. Singh A, Lesica NA: Incremental Mutual Information: A New Method for Characterizing the Strength and Dynamics of Connections in Neuronal

*Correspondence: cooneycj@maths.tcd.ie

Mathematical Neuroscience Lab, School of Maths, Trinity College Dublin, Ireland

\section{BioMed Central}

(0) 2012 Cooney and Lynch; licensee BioMed Central Ltd. This is an Open Access article distributed under the terms of the Creative Commons Attribution License (http://creativecommons.org/licenses/by/2.0), which permits unrestricted use, distribution, and reproduction in any medium, provided the original work is properly cited.
Circuits. PloS Comput Biol 2010, 6(12):e1001035, doi:10.1371/journal. pcbi.1001035

3. Newman MEJ: Modularity and community structure in networks. PNAS 2006, 103(23):8577-8582, doi: 10.1073/pnas.0601602103.

doi:10.1186/1471-2202-13-S1-P92

Cite this article as: Cooney and Lynch: Determining information flow through a network of simulated neurons. BMC Neuroscience 201213 (Suppl 1):P92.

Submit your next manuscript to BioMed Central and take full advantage of:

- Convenient online submission

- Thorough peer review

- No space constraints or color figure charges

- Immediate publication on acceptance

- Inclusion in PubMed, CAS, Scopus and Google Scholar

- Research which is freely available for redistribution Submit your manuscript at
www.biomedcentral.com/submit C Biomed Central 